\title{
VLT: CONSTRUINDO UM NOVO SIGNIFICADO PARA A ÁREA CENTRAL DO RIO DE JANEIRO
}

\author{
Flávio Tavares Brasileiro \\ Universidade Federal de Pernambuco \\ Orientador: Zeca Brandão \\ flaviotavares.cidade@gmail.com
}

\section{RESUMO}

Esta pesquisa aborda o retorno do bonde moderno (VLT) à cidade contemporânea. Discutimos esse movimento de retorno a partir de um processo de valorização deste veículo como vitrine dos processos de transformação urbana nas cidades, que se iniciaram no continente europeu e se espalharam por várias cidades pelo mundo, o que terminou por alçar o VLT à condição de ícone dos processos de renovação urbana. À luz da experiência de reinserção destes veículos nos centros das cidades francesas, que se deu a partir de uma metodologia muito própria, bem como a experiência barcelonesa nos anos de 1990, com todo um contexto de requalificação dos espaços públicos e retomada do valor da urbanidade, usamos como tela de discussão neste artigo as bases teóricas que sustentam a pesquisa de mestrado que investiga o papel dos trilhos na construção de uma nova imagem urbana na cidade do Rio de Janeiro, Brasil.

Palavras-chave: VLT, renovação urbana, marketing urbano, imagem urbana

\begin{abstract}
This research accesses the recurrence of light rail vehicles (LRV) in contemporary cities. This recurrence movement is discussed through a process of valuing this vehicle as a showcase of urban transformations in the cities, which have began in the European Continent and spread through several cities around the world, ending up with the elevation of the LRV to the status of a urban renewal processes icon. In the light of the reintegration experience of this vehicles in the centers of French cities, which was based on a very particular methodology, as well as the experience of Barcelona in the 90's, with a whole context of public spaces requalification and resumption of urbanity value, we have used as a background in this article the theoretical bases that support the masters research which investigates the role of rails in the construction of a new urban image in the city of Rio de Janeiro, Brazil.
\end{abstract}

Key words: LRV, urban renewal, urban marketing, urban image 


\section{INTRODUÇÃO}

Desde que os bondes começaram a sair do cenário das cidades até a primeira metade do século $\mathrm{XX}$, em contraposição à contínua ascensão dos automóveis, uma completa alteração morfológica foi se desenhando no espaço viário urbano. Sabe-se que os transportes imprimem com muita força traços morfológicos que marcam a fisionomia das cidades. Mais que isso, os padrões de deslocamento e a relação destes com os modais disponíveis à época contribuíram por caracterizar tipos de cidades, com efeitos diretos nos modos de vida e urbanidades. Isso resultou, a depender da priorização dada a cada um em determinado espaço de tempo, em uma imagem de cidade particular.

"[...] el transporte público tiene que reivindicar su papel de estimulador de la vida de la ciudad, siempre y cuando cumpla con sus irrenunciables funciones de acceso, y creador de nuevas posibilidades de movimiento y comunicación. Por ello es, por lo que en esos lugares públicos de encuentro de personas y culturas, los conceptos de prestigio, modernidad, durabilidad y elegancia han de predominar, forjando una imagen amable y dinámica del transporte público que redundará directamente en el aumento de usuarios y en su fidelidad" (Crespo, 2009 apud Schade, 2011:53).

A alteração imposta pelo rodoviarismo talvez tenha sido a mais marcante na história das cidades. O protagonismo dado aos carros resultou em modelos de rua essencialmente baseados na circulação motorizada, contribuindo para mudar de vez o conceito da rua (enquanto espaço público) para um elemento apenas de passagem. Esse modelo passou a ter ressonância na maioria das cidades do planeta.

As grandes modificações dos sistemas de transporte nas cidades causam um impacto estrutural no uso do solo, mediado por uma alteração na acessibilidade do local. A cartilha do Projeto Portal elucida mostrando que "uma maior acessibilidade aumenta a atração de um local para todos os tipos de uso do solo, deste modo influencia a direção do novo desenvolvimento urbano" (Projeto Portal, 2003).

Os impactos do uso do solo nos transportes foram (e ainda são) bastante estudados, e hoje conseguimos identificar os tipos de transporte mais adequados a determinados tipos de ocupação. No entanto, o impacto contrário (dos transportes no uso do solo), ainda é pouco conhecido, sendo poucas as tentativas de induzir determinados efeitos na cidade a partir da manipulação de um modal. Esse contexto é favorecido, em grande medida, pelo fato de que na maioria das cidades a gestão da mobilidade ainda é um caso tratado exclusivamente pela engenharia de transporte, desconsiderando o papel que a arquitetura e urbanismo tem de transformação do território.

O fato é que o surgimento do automóvel particular, mais do que uma solução tecnológica para resolver um problema de deslocamento, mas como expressão de um momento econômico que vai se tornar símbolo do capitalismo por muito tempo, gerou uma série de transformações na configuração interna das áreas urbanas. Com isso, problemas generalizados também foram surgindo, afetando diretamente a população, tanto em termos locacionais e ambientais, quanto de seu perfil econômico e social. Com isso, surgiram também sucessivos experimentos de contestação a esse modelo.

Uma destacada experiência iniciada para reverter a lógica de priorização automotora que tinha tomado conta das suas cidades aconteceu na França. A partir da década de 1970, começou-se a explorar novos modos de transportes alternativos, que culminou na realização de um concurso, onde elegeu-se o bonde moderno Alstom (bonde francês standart - TFS) como veículo capaz de promover essa transformação. A partir de então, o país deu início a uma experiência estratégica de incentivo maciço à construção de vias de bondes modernos em seus centros históricos, com a finalidade explícita de resignificar os seus espaços públicos a partir de um conceito chamado de "urbanização induzida" (Castro, 2007), já que eles conseguiam a partir da inserção desses bondes, efeitos para além da melhora da mobilidade.

Desde então esse sistema de bonde moderno, conhecido no Brasil por Veículo Leve sobre Trilhos (VLT), vem conquistando espaço em dezenas de cidades europeias, que buscam reverter a lógica de priorização automotora. Tais cidades apostam em uma opção de transporte de massa, embora não abram mão da escala humana que a interface de operação contemporânea deste veículo possibilita. Os exemplos mostram que as cidades tentam explorar com ele o lado "lúdico" do transporte coletivo.

"Embora, durante muito tempo, a ideia do transporte estivesse ligada à possibilidade de animação, de abertura ao mundo da cultura, que o automóvel soube muito bem personificar, o transporte coletivo sempre esteve ligado a um lado mais racional e operacional. Com o reconhecimento desta dimensão no transporte urbano, 
abrem-se novas possibilidades para o serviço em si do transporte, onde não se pode esquecer que a afeição popular é um fator decisivo da eficácia dos transportes coletivos. Ou seja, embora os transportes coletivos possam ser reconhecidos por viabilizar os deslocamentos obrigatórios diurnos, há ainda muito a ser explorado pelo seu lado lúdico" (Izaga, 2009:30).

Com isso, diversas zonas centrais começaram a (re)adaptar-se morfologicamente para recebe-lo. Passou-se a usar a necessidade desse redesenho viário que o VLT exige para operar, como uma oportunidade para readaptar o desenho urbano da cidade à uma escala humana.

Esse movimento vinha acompanhado do forte processo de pedestrianização que acontecia na Europa, e que levou o estudioso alemão de zonas pedestrianizadas, Monheim (1990 apud Tejedor 2009), a falar que uma cidade sem área pedestrianizadas representativas parecia agora desesperadamente antiquada. O VLT surgia como um aliado nesse processo, já que se encaixava nas novas condições morfológicas e desfrutava de forte prestígio pelo apelo de design futurista do veículo, com largos painéis envidraçados e linhas suaves e arredondadas. Essa condição do design não era simplesmente uma questão de elegância, mas relacionavase sobremaneira com o papel de inserção dele na paisagem, onde o passageiro tornava-se condição integrante da mesma, e não apenas simples observador - contribuindo para a experiência de fruição da cidade.

Assim, passava-se a entender a inserção desse sistema de mobilidade não mais como "uma simples ação pragmática baseada apenas em técnicas de engenharia, construção e gerenciamento" (Castro, 2007:43), que resolveria os problemas de acessibilidade. Sua implantação passava a ser entendida, segundo Castro (2007), enquanto uma "operação política", onde utilizou-se o bonde como vetor do debate sobre a renovação urbana: "este debate fornece oportunidade para um questionamento global do urbanismo: o embelezamento das vias públicas, a revitalização dos centros, as novas operações imobiliárias, a renovação dos bairros degradados, a pertinência de equipamentos públicos" (Castro, 2007:43).

Esse movimento de valorização do veículo como vitrine dos processos de transformação urbana se tornou crescente, e se espalhou por várias cidades além do continente europeu, contribuindo para alçar o VLT à condição de ícone dos processos de renovação urbana. Criou-se com isso uma ideia de que há uma relação direta entre a implantação do modal e a dita renovação.

De modo não casual, a implantação desses veículos vêm frequentemente atrelada a grandes projetos urbanos, onde se gera uma variação positiva nos valores imobiliários, gerando uma reação em cadeia, "abrangendo processos econômicos, sociais, políticos e espaciais, tais como mudanças quantitativas e qualitativas no uso do solo urbano, mobilidade social e espacial da população residente nas áreas afetadas pelo sistema, apropriação privada das rendas fundiárias geradas pelo setor público etc" (Farret, 1984:24).

Assim, levantamos como objeto empírico de análise a área central do Rio de Janeiro, cidade que implantou o VLT com base em um discurso de que este seria uma peça-chave ${ }^{1}$ no projeto de revitalização urbanística ocorrido no centro da cidade em função dos Jogos Olímpicos de 2016. A vemos, por isso, como um recorte singular para analisar quais alterações de fato estão ocorrendo no espaço público quando da inserção do modal, de modo que poderemos encontrar relações objetivas que indiquem se a introdução do modal está associada à construção de uma nova imagem urbana (e que imagem seria essa) - ver figura 1.

\footnotetext{
1 "O Projeto VLT do Rio [...] consiste no principal componente de infraestrutura de transporte da operação urbana consorciada da região do porto, também denominada de projeto Porto Maravilha" (Grupo CCR, 2011).
} 


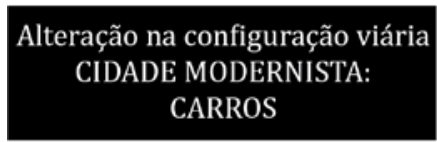

"The french touch" CIDADE CONTEMPORÂNEA: VLT
Paisagem

Desenho urbano

Valorização imobiliária

A introdução do VLT está associada à construção de uma nova imagem urbana?

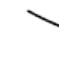

"EFEITOS COLATERAIS"

IMAGEM URBANA

Figura 1: Desenho do problema de pesquisa.

Elaborado pelo autor.

\subsection{Metodologia}

Este artigo apresenta um pequeno recorte do cerne da problematização desenvolvida na pesquisa de mestrado do Programa de Pós Graduação em Desenvolvimento Urbano (MDU/UFPE), denominada "O VLT e a reinvenção urbana - o papel dos trilhos na construção de uma nova imagem urbana carioca".

Dita investigação partiu de uma experiência prática do pesquisador durante um ano vivendo em uma cidade europeia transformada pelos trilhos ${ }^{2}$, de onde começaram a emergir evidências referentes à causalidade da dinâmica alcançada pelo centro da cidade de Sevilha, Espanha. Em sucessivos novos contatos com outras cidades europeias que apresentavam dinâmica semelhante, começaram a se formar conjecturas sobre a inserção do VLT em centros urbanos ${ }^{3}$. Desta forma, consubstanciava-se uma problematização para uma pesquisa de mestrado baseada, segundo Lakatos e Marconi (2003), no método hipotético-dedutivo.

Teria a introdução do modal associação com a construção de novas imagens urbanas? Construída a problematização foi possível identificar um lócus de estudo sensível à confrontação dos argumentos. A área central do Rio de Janeiro tornou-se então, o objeto empírico desta pesquisa - a região foi transformada para atender a um novo perfil de cidade em função da realização das Olimpíadas.

Assim, encontramos um caso para aprofundar o estudo, de modo que pudemos fazer uma análise que valorizasse o objeto sobre o sujeito. Esse tipo de estudo de caso nos permitiu, por exemplo, fazer o exame dos projetos levados a cabo na Operação Urbana Consorciada Porto Maravilha (na qual se insere o "VLT Carioca"), e observar a partir disso os efeitos (esperados e efetivados) de transformação urbana na região. Apesar da área central do Rio vir sendo objeto nos últimos anos de inúmeros estudos acadêmicos, o recorte que trazemos parece-nos efetivamente original no seu propósito de fazer a análise reversa, colocando o VLT como protagonista do estudo das transformações da zona.

Essa análise se deu a partir de uma pesquisa qualitativa, já que para fazer avaliações mais quantitativas seria importante uma acomodação da realidade após a inauguração efetiva das linhas propostas, de modo a perceber o cenário de transformação do antes-durante-depois. Passado pouco mais de um ano dos Jogos Olímpicos de 2016, as linhas ainda não estão funcionando em sua capacidade plena de operação - sendo difícil avançar em qualquer análise mais precisa através de dados que dependam dessa funcionalidade integral.

Assim, desenhamos uma pesquisa com base em três indicadores de avaliação de impactos propostos por Farret (1984), levantados no nosso referencial teórico, que relacionarão a configuração urbana, os fatores socioeconômicos, e o ambiente. A configuração urbana foi ressaltada através dos mapas da região, onde foram destacados os projetos implantados e a morfologia resultante; os fatores socioeconômicos perpassam o indicador de configuração urbana, pois traz sobremaneira um fator associado aos usos do solo instalados; e o ambiente, como fator resultante da combinação de todos esses fatores, que na verdade

\footnotetext{
${ }^{2}$ Durante os anos de 2013 e 2014 por ocasião da graduação-sanduíche na Escuela Técnica Superior de Arquitectura da Universidad de Sevilla, na Espanha.

${ }^{3}$ Alguns ensaios dessas inquietações foram publicados no Brasil, destacando-se o da Revista aU:

RIBEIRO, TAVARES. (2015) O VLT em novas interfaces - contribuições para uma visão humanizada dos centros históricos. Revista AU - Arquitetura e Urbanismo (São Paulo), 258, 58-61.
} 
anuncia uma expressão urbana típica desses fatores próprios, ou seja, nos apresenta uma dinâmica da paisagem urbana que caracteriza determinadas imagens de cidade.

Com isso, pudemos estabelecer relações com outras cidades que passaram por processo semelhante, gerando uma síntese, que dimensionou o impacto gerado pela implantação do VLT - corroborando ou não com o argumento inicial.

\subsubsection{Procedimentos metodológicos}

O tema que serviu de mote para esta investigação levou ao desenvolvimento de três discussões diferentes, embora conexas. O urbanismo induzido e os impactos do VLT, que despertou a investigação; a reinvenção urbana e todo o seu aspecto socioeconômico, que permeia todo Grande Projeto Urbano; e o centro do Rio de Janeiro, área de intervenção do projeto Porto Maravilha. No recorte trazido neste artigo, buscaremos apresentar as premissas teóricas de base, que são o conceito de urbanismo induzido e a discussão sobre renovação e marketing urbano e apresentar seus primeiros elementos conclusivos que ratificam o argumento apresentado.

A metodologia geral da pesquisa baseou-se na investigação de um caso específico, lançando para isso um quadro teórico de base. Esse contexto teórico foi construído na forma padrão de uma revisão de literatura. Foi realizada uma extensa pesquisa bibliográfica, de maneira a levantar dados em outras pesquisas (teses, dissertações, artigos) para comparar evidências referentes à causalidade da dinâmica alcançada por outras cidades pelo mundo.

Este procedimento analítico foi feito de modo contínuo, e as etapas se desenvolveram em estágios interrelacionados e muitas vezes sobrepostos. Por exemplo, de maneira a compreender o processo de transformação dinâmica específica do Porto Maravilha (objeto empírico), necessitou-se ter antes, uma base teórica das evidências e conclusões atestadas por outras pesquisas em objetos semelhantes, no entanto, as visitas em campo na área de estudo foram mantidas periodicamente mesmo sem a conclusão das outras fases.

Assim, visitou-se a região enquanto observador participante em três ocasiões-chave: (1) na época das obras de implantação do VLT, permitindo visualizar a transformação urbanística e fazer registros fotográficos do processo de mutação da área; (2) quando da sua implantação, no mês da inauguração do VLT e da realização dos Jogos Olímpicos, evento-fim de todo o arranjo gestado para a implantação do modal, e (3) no fim desse trabalho investigativo, que nos permitiu fazer uma última avaliação do cenário antes da conclusão dessa pesquisa, possibilitando o reconhecimento dos primeiros impactos.

A segunda grande etapa focou na coleta e análise de documentação indireta, através da pesquisa documental. Esta foi desenvolvida apenas após a consolidação de boa parte da etapa anterior, sendo importante pois, enquanto pesquisador, já podíamos ter domínio da situação local e de comparações com outros estudos em contextos geográficos diferentes - podendo proceder uma melhor coleta para posterior análise.

A etapa de coleta desses dados primários apresentou-se como fundamental para o resultado da pesquisa, pois mediante um sistemático trabalho de investigação e compilação ao longo de dois anos de documentos escritos, peças publicitárias, reportagens, entrevistas e inclusive dossiês (que embora públicos foram extremamente abafados mediante o cenário político que se gestava os processos), conseguiu-se variados elementos que subsidiaram o desenvolvimento do argumento inicial.

São exemplos do material sistematizado e analisado, os contratos para a efetivação da Parceria PúblicoPrivada (PPP) "VLT Carioca", o Dossiê da Controladoria Geral da União (CGU) que apontou as brechas na execução do processo, ou mesmo os não escritos, como os mapas produzidos pelo GRUPO CCR (2011), assim como os projetos de reurbanização que envolvem a área, disponibilizados ao longo do tempo eletronicamente pela Companhia de Desenvolvimento Urbano da Região do Porto do Rio de Janeiro (CDURP).

A terceira etapa dedicou-se à pesquisa de campo de forma mais sistematizada e planejada. Ainda que ela tenha sido feita ao longo das demais etapas, reservou-se um tempo final para fazer levantamentos mais específicos e estudos analíticos mais precisos. 
Assim, procedeu-se o desenvolvimento de uma série de sete mapas que colocam as linhas do VLT como protagonista de um conjunto de informações captadas ao longo de todo o tempo de desenvolvimento da pesquisa. O mapa é focado na zona central do Rio de Janeiro e destaca o perímetro da OUC Porto Maravilha e o traçado final das linhas de VLT. De acordo com um agrupamento de informações foi possível visualizar a configuração urbana interagindo com alguns elementos propostos nos discursos, tais como: as principais alterações espaciais resultantes desse processo de transformação na área; a rede inicial com suas 9 linhas propostas; a rede prioritária, destacando as 4 linhas determinadas como prioritárias para a gestão; e a rede construída até as Olimpíadas, com as fases para se chegar nas 2 linhas inauguradas até agora e os trechos ainda restantes.

Posteriormente, outros atributos do ambiente urbano vão se somando à analise configuracional urbana, quando, por exemplo, cruzamos o mapa da rede implantada com a rede de integração modal (figura 5), verificando a articulação deste com os sistemas existentes na cidade. Como conclusão dessa série de elementos de análise, trazemos os projetos implantados no Porto Maravilha de modo a somar outros atributos de análise socioeconômicos, como o que evidencia os principais equipamentos e pontos turísticos da região e os projetos implantados a partir da OUC Porto Maravilha (figura 6).

Com o apoio da clareza visual do que estes mapas nos mostram de interferência ao longo das linhas do VLT, sentiu-se a necessidade de uma quarta fase conclusiva, para sanar questões surgidas da análise desses mapas com as análises documentais da fase anterior. Assim, realizamos algumas entrevistas semiestruturadas com pessoas chave para obter tais respostas na concessionária VLT Carioca: O Gerente de Engenharia, José Carlos Alves e o Coordenador de Engenharia Operacional, Rafael Halliday.

Ainda, a partir desta entrevista, conseguimos ter acesso a duas importantes pesquisas de satisfação realizadas pela concessionária anualmente, a primeira entre novembro e dezembro de 2016, realizada pelo Instituto Ibope, e a segunda no mesmo período do ano em 2017, realizada pelo Instituto Datafolha. Assim, por fim, pudemos cruzar os elementos de análise levantados ao longo de toda a trajetória dissertativa para analisar os efeitos esperados e efetivados de transformação urbana na área.

\section{URBANISMO INDUZIDO - O PODER DOS TRANSPORTES NA CIDADE}

O testemunho mais antigo da existência do homem no planeta Terra é de 3.700 .000 anos. Sabe-se disso através da marca de um Australopithecus Afarensis, que caminhava com seu filho e teve sua marca solidificada no lodo vulcânico de Laetoli, na Tânzania (Careri, 2009:35).

Esse foi (e ainda é) o meio de transporte inerente ao ser humano. Foi a partir dele que surgiram as primeiras civilizações, construídas sempre à sua escala, induzidas por um critério: até onde os pés humanos conseguiam alcançar. Assim surgiram os primeiros caminhos, ruas e bulevares, "todos espaços para movimentação linear, projetados com base no sistema humano de locomoção" (Gehl, 2015:33).

Tal parâmetro induziu a conformação de um tipo de urbanização, caracterizada nas chamadas cidades tradicionais ou orgânicas. "Viajava-se a pé e as técnicas de construção se baseavam na experiência de gerações. Daí resultavam cidades em uma escala adaptada aos sentidos e ao potencial dos seres humanos" (Gehl, 2015:55). Ou seja, a forma da cidade, e as suas transformações físicas ocorridas até então eram limitadas, a ponto de podermos considerar, tal qual comenta Izaga (2009) que as cidades existem por causa do movimento.

Ao longo do tempo novas tecnologias vão permitir ao homem melhorar a sua eficiência no deslocamento, desde o aproveitamento da força animal, com elementos de tração, até chegar em sistemas ferroviários avançados que percorrem o subterrâneo das cidades. Sort (2005) comenta que a história do desenvolvimento do sistema de transportes é marcada pela inexistência de um modelo configurado de uma vez por todas, e sim uma constante e contínua adaptação das infraestruturas e demandas da cidade às possibilidades dos avanços tecnológicos, à competição no espaço com outros sistemas de transporte e finalmente à capacidade financeira pública ou privada para construí-los.

A partir de um estudo da evolução dos modos de transporte (Newman, Kenworthy, 1999:27; Rodrigue et al., 2006:186), Izaga (2009:54) evidencia a compartimentação em três grandes eras: A Cidade do Pedestre ou das carruagens de tração animal (1800-1890), a Cidade do Trânsito (Transit City) ou do bonde elétrico (18901920) e a Cidade do Automóvel (1930-hoje). 
Essa primeira grande fase de independência dos motores foi chegando ao fim com o crescimento populacional e, sobretudo, o industrial, por volta de 1860, quando as distâncias na marcha a pé não conseguiam mais alcançar o todo da cidade. Foi assim que surgiram os transportes sobre trilhos, segundo Izaga (2009), os Trens (primeiro a vapor e depois elétricos), e os bondes (inicialmente puxados por cavalos, depois a vapor e posteriormente elétricos), que permitiam os deslocamentos com maior velocidade, e que permitiram que as cidades se estendessem por cerca de vinte a trinta quilômetros, fazendo com que a densidade caísse pela metade do padrão a pé anterior (entre 50 a 100 pessoas por hectare).

Nesse contexto "evolutivo", cabe destacar a conjuntura econômica do final do século XX, com a forma de organização da produção industrial pelos princípios do Fordismo, que revolucionou os transportes a partir da introdução de um novo símbolo da tecnologia, avanço e modernidade: o automóvel. As ações pioneiras de Henry Ford fizeram com que o automóvel, nas palavras de Maricato (2008) passassem a ser uma necessidade de todos. Esse processo trouxe uma forte repercussão espacial nas nossas cidades, que induziram um novo processo urbanizador, de dispersão e fragmentação do tecido urbano. "O automóvel conformou as cidades e definiu, ou pelo menos foi o mais forte elemento a influenciar, o modo de vida urbano na era da industrialização" (Maricato, 2008:6).

O impacto espacial desse meio de transporte resultou em territórios de baixa densidade, entre 10 a 20 pessoas por hectare segundo Izaga (2009), onde precisou-se planejar a cidade, agora, a partir de zonas. Com a proliferação dos automóveis, esse processo de segmentação espacial "dá lugar ao fenômeno de conurbação induzindo o surgimento de áreas metropolitanas" (Izaga, 2009:55, grifo nosso).

Findo estes três grandes ciclos de urbanização, podemos ver como a imagem das cidades podem ser caracterizadas pelas mudanças nos meios de transporte, que constituem o elemento central da estruturação do espaço urbano: "los modos de transporte predominantes exigen la construcción de nuevas infraestructuras que permitan la extención de la urbanización durante un periodo de crecimiento y que denominamos 'salto de Umbral'" (Magrynià, Marzá, Feliu, 2009 apud Schade, 2011:10).

É importante perceber que essa imagem é espelho de um processo mais amplo e complexo de uma reestruturação que afeta os padrões de distribuição das atividades econômicas e dos valores do solo, onde está implícita nessa correlação a noção de impactos, ou seja, "o conjunto de efeitos ocorridos em um destes sistemas por ações produzidas sobre o outro e vice-versa" (Farret, 1984:21).

Assim, as tentativas de alterações no sistema de mobilidade por meio das mutações nos sistemas de transporte possuem dupla interação e vão reverberar diretamente na acessibilidade, um "valioso recurso" segundo Farret (1984), que "têm profundas implicações sobre a vida política, econômica e social da comunidade, numa cadeia de eventos de difícil delimitação" (Farret, 1984:22).

"Via de regra, melhorias introduzidas no sistema de transporte urbano produzem a ampliação na acessibilidade e, como consequência, a elevação dos valores imobiliários; esta, por sua vez, aciona um processo de mobilidade intra-urbana, com as famílias de renda mais baixa sendo substituídas pelas de renda mais alta ou usos não-residenciais, no caso do aumento da acessibilidade ser mais valorizado que as externalidades negativas da intervenção, como por exemplo o aumento do volume de tráfego, do ruído, da poluição etc. Na situação inversa ocorre de as famílias de renda mais alta serem substituídas pelas de renda mais baixa, num processo de 'filtragem sócio espacial'" (Farret, 1984:30).

Segundo a cartilha "Transportes e Uso do Solo" elaborada na União Europeia (2003), a principal abordagem teórica para explicar esta forma dupla de interação de uso do solo e transportes em áreas metropolitanas inclui teorias técnicas (sistemas de mobilidade urbana), teorias econômicas (cidades como mercados) e teorias sociais (sociedade e espaço urbano).

A escolha dos modais, portanto, precisa estar atenta a esses três componentes, embora muitas vezes alguns sejam deliberadamente negligenciados. Isso acontece comumente quando se pensa no sistema de mobilidade urbana apenas como um componente funcional para se resolver o deslocamento de um ponto ao outro, ou quando do contrário, se utiliza o componente modal como uma estratégia de alavanque de transformação do espaço urbano e social.

Com as cidades dilaceradas pelas grandes obras viárias, principalmente a partir da década de 50 , que privilegiam o automóvel, e empreendem um crescente processo de desumanização da cidade, o homem vem 
sendo afastado do ambiente urbano. De modo muito recente, já a partir dos resultados negativos desse tipo de ambiente, tem surgido uma consciência da importância do espaço público como uma interface capaz de produzir urbanidade. "En este sentido, el espacio público como interface se entiende como el elemento que articula las funciones, usos y actividades de la relación entre transporte público-espacio público existenteentorno, como las necesidades de movilidad y accesibilidad dentro de un sistema común: la ciudad" (Schade, 2011:10).

Izaga (2009) nos lembra que a experiência de Barcelona nos anos 1990 foi "sinalizadora de uma retomada do valor da urbanidade, articulada pela requalificação dos espaços públicos", de onde, segundo ela, o Projeto Rio Cidade desenvolvido no Rio de Janeiro entre 1993 e 1997 teve inspiração metodológica. Por trás destas iniciativas haveria "a ideia de associar ao projeto viário um projeto urbano para criar um verdadeiro espaço público" (Izaga, 2009: 80), que contemplam novos modais, cada um com avanços técnicos e de desenho, que juntos, "são determinantes na mudança da imagem e da relação destes com o espaço público e o meio" (Schade, 2011:53).

Essa experiência espanhola é paradigmática e nos serve como interessante base analítica, na medida em que traz consigo uma transformação fundada no transporte ferroviário urbano. Esse tipo modal acentua os efeitos de impacto, por serem estruturas "rígidas" com traçado fixo. "...por sus características intrínsecas, difícilmente cambiará el recorrido preestablecido, exigiendo más responsabilidad a los planificadores y otorgando mayor certeza a los inversores" (Bullaude, 2003 apud Schade, 2011:12).

Essa "responsabilidade" tratada por Bullaude é, na verdade, o reconhecimento de que o transporte ferroviário atua como forte definidor do espaço público, na medida em que determina "uma relação mais direta com o entorno porque densifica e diversifica as dinâmicas urbanas (usos, atividades e funções), aumentando a complexidade existente no espaço público, produto de uma melhor acessibilidade. [...] A soma dos condicionantes mencionados permitiu que o transporte ferroviário urbano se consolide como um elemento de estruturação, ordenação e regeneração urbana: sua inserção no meio urbano fica determinada fortemente pela definição do espaço público" (Schade, 2011:12, tradução nossa).

Cumpre salientar que esse efeito multiplicador dos impactos, nos casos desses transportes sobre trilhos urbanos, atuam para modificar a "imagem da cidade", na medida em que suas mudanças atuam, conforme salienta Schade (2011) na recuperação da confiança e segurança das pessoas, mudando hábitos de consumo e até tendências das intervenções imobiliárias.

Por fim, concluímos até aqui que a área de influência dos sistemas de transportes sofrem impactos em vários níveis, sendo estes, potenciais modificadores e caracterizadores das imagens de cidades que temos ao longo de períodos marcados pela presença predominante de um sistema modal. Farret (1984) sugere a classificação destas categorias de impactos em três tipos: (a) Indicadores vinculados à configuração urbana; (b) Indicadores ambientais; (c) Indicadores socioeconômicos, os quais poderão ser um importante guia na avaliação do papel que o VLT vem assumindo na possibilidade de geração desses impactos. Estas, serão norteadoras para as nossas análises dos tópicos seguintes.

\section{A RENOVAÇÃO URBANA DAS ÁREAS CENTRAIS. UMA SINA?}

Por todo um processo histórico de construção, que permite grande força morfológica em relação ao todo da cidade, bem como pelo simbolismo que ele desempenha em relação às atividades da urbe, os centros "têm sido identificados como o lugar mais dinâmico da vida urbana, animado pelo fluxo de pessoas, veículos e mercadorias" (Vargas, Castilho, 2006:1). Esse somatório de forças históricas e diversidade é basicamente o que caracteriza a definição de centro que Carrion (1998 apud Vargas, Castilho, 2006:3) nos traz: uma cidade de diversidade étnica, portadora de processos históricos conflituosos, com milhares de anos de existência em permanente contradição.

Diz-se que esses conflitos são portadores de "processos históricos conflituosos", pois com o avanço da sociedade, novas marcas e novas dinâmicas vão sendo construídas e, com isso, precisam disputar o seu lugar nesse ambiente marcado por simbologias consolidadas. Diz-se que esses conflitos estão em "permanente contradição", pois o apelo histórico dessas zonas são muito presentes no imaginário social, ao passo que as demandas da sociedade contemporânea impõem novos valores para os espaços urbanos, sendo os centros, no mundo contemporâneo, "parte integrante das vitrines urbanas e devem sintetizar a sua 'boa e bela' imagem para garantir uma vantagem competitiva entre as cidades" (Vargas, Castilho, 2006:46). 
A esses processos de constante modificações e alterações do espaço urbano estão ligados conceitualmente as intervenções "res", que dão forma, de acordo com cada intenção política ou desejo urbanístico a mecanismos específicos de atuação na cidade. Segundo Portas (1985), por "intervenção na cidade existente", "deveriam ser entendidas as iniciativas do poder público ou de setores privados que visem a reestruturação ou revitalização funcional do tecido urbano (atividades e redes de serviços); a sua recuperação ou reabilitação arquitetônica (edificação e espaços não construídos, designadamente os de uso público); e a sua reapropriação social e cultural (grupos sociais que habitam ou trabalham em tais estruturas, etc)" (Portas, 1985 apud Kara José, 2012:12).

Todas essas intervenções, portanto, partem de um pressuposto de que tal ambiente não atende mais a determinado padrão, e vive, em algum nível, um processo de deterioração urbana. Vargas e Castilho (2006) falam que deteriorar é equivalente a estragar, piorar e inferiorizar, e assim fazem um paralelo de como esse processo de intervenção ocorre nas ciências biológicas, onde "intervenção e cirurgia são palavras sinônimas, e o organismo submete-se a uma intervenção basicamente em três situações: para a recuperação da saúde ou manutenção da vida; para a reparação de danos causados por acidentes e, mais recentemente, para atender às exigências dos padrões estéticos" (Vargas, Castilho, 2006:3).

Vemos assim, que as possibilidades de intervenção podem nascer a partir de variadas causas, no entanto, a sua identificação ou "diagnóstico" guardam estreita correlação com um contexto ideológico, e passam a ser ativados, em geral, a partir de uma motivação de ordem política. Na cidade, esse desejo parte do entendimento de que essas intervenções são capazes de alterar a sua imagem, e que esta, por sua vez, pode ser um elemento importante para atrair capital e pessoas.

Essa atração está intimamente ligada com a revalorização simbólica destes espaços considerados degradados. Quase sempre estas degradações relacionam-se ao declínio econômico do ambiente, que podem vir a partir da "perda de sua função, ao dano ou à ruína das estruturas físicas, ou ao rebaixamento do nível do valor das transações econômicas de um determinado lugar" (Vargas, Castilho, 2006:3). Esse cenário se traduz urbanisticamente com a chegada de Grandes Projetos Urbanos, onde a cidade contemporânea se transforma para ser "puro espetáculo, selecionada por um visual programado e projetado" (Boyer, 1998).

\section{A BUSCA POR UMA NOVA IMAGEM URBANA CARIOCA}

Como já ensejamos nos tópicos anteriores, com a proliferação de cidades com o sistema de bondes modernos implantado, uma espécie de "mitificação" foi sendo criada, a ponto de estabelecer uma ideia de que há uma relação direta entre a implantação do modal e a renovação urbana da região da sua implantação. Ou seja, foi-se estabelecendo um princípio de que a renovação urbana é uma sina. Tal princípio incute a ideia que, através das estratégias de marketing urbano, todas as cidades agora precisam alcançar determinado patamar de infraestrutura para não parecerem atrasadas.

Tal patamar de infraestrutura guarda relação, na verdade, com as novas condições de trabalho impostas por essas empresas da "nova economia", onde segundo Castells e Borja (1997), a competitividade destas depende fortemente das condições de produtividade no âmbito territorial que operam. Assim, o princípio dos grandes projetos urbanos é "criar cenários apropriados nos quais as empresas possam encontrar infraestrutura, meios de transporte, equipamentos e serviços que as permitam funcionar a escala internacional, regional e nacional" (Cuenya, 2011:189).

Um conjunto de tipos de ações vêm se repetindo na aplicação desses projetos. Dentre eles têm tido destaque, justamente, as infraestruturas de transporte, que são naturalmente projetos de grande envergadura por meio dos quais se conseguem promover uma reestruturação urbana. É nesse contexto que ressurge o bonde na cidade, o qual utilizaremos como vetor dessa discussão crítica da busca por uma nova imagem urbana, já que ele volta com uma imagem de veículo futurista, com design elegante e integrado à paisagem urbana. $\mathrm{O}$ exemplo francês volta a ser referência para a promoção positiva desse tipo de imagem de cidade.

"As realizações das primeiras linhas de bonde francesas são hoje citadas como exemplos em toda a Europa. Essa repercussão positiva foi largamente utilizada pelas cidades pioneiras para a construção de uma nova imagem urbana. Nos projetos recentes, esta imagem valorizante do bonde tem sido utilizada tanto na esfera local quanto fazendo parte de uma estratégia promocional que pode ser qualificada de city marketing. [...] A preocupação em criar uma linha de transportes com grande impacto visual e um espaço público espetacular corresponde a um objetivo de atrair investimentos, turistas, novas empresas e novos contingentes de população" (Castro, 2007:73). 
No caso do Rio de Janeiro, a implantação do VLT teve como base um discurso de que este seria uma peçachave no projeto de revitalização urbanística ocorrido no centro da cidade em função da realização dos Jogos Olímpicos de 2016. As transformações na produção do espaço urbano seriam, portanto, capitaneadas pela implantação destes veículos.

Para isso, um complexo arranjo entre agentes produtores do espaço, que incluiu os três níveis de governo (municipal, estadual e federal) e entidades internacionais, foi gestado para possibilitar essa nova configuração moderna da área central. Estes, lançaram mão de uma série de modernos instrumentos urbanísticos regulatórios e de financiamento, sob a regência da grande OUC Porto Maravilha, e da PPP do "VLT Carioca".

A estratégia promocional do bonde moderno (VLT) por outro lado, está alinhada a um traço estrutural dos grandes projetos desde o ponto de vista da sua articulação com a estrutura urbana que é, segundo Cuenya (2011), sua capacidade para produzir um aumento extraordinário na rentabilidade do solo em áreas estratégicas. Desta forma, tem sido recorrente a utilização do VLT como um elemento capaz de catalisar processos de transformação urbana, onde dentre os principais efeitos colaterais resultantes desta, está a valorização imobiliária.

A análise que trazemos nesta pesquisa parte, portanto, do pressuposto de que essas "mega operações se implantam em determinadas zonas que ficaram relegadas, mas que resultam estratégicas desde o ponto de vista da sua acessibilidade e possibilidade de transformação urbanística e valorização" (Cuenya, 2011:187). Percebemos que o processo de gestão das ações que resultaram na implantação do VLT são processos deliberados, condizente com os manuais de planejamento estratégico que, segundo Vainer et al (2012), disseminaram essas ideias a partir dos anos 1990, como modelos de atuação e de experts para a gestão municipal, induzindo a promoção, o crescimento econômico e a competitividade.

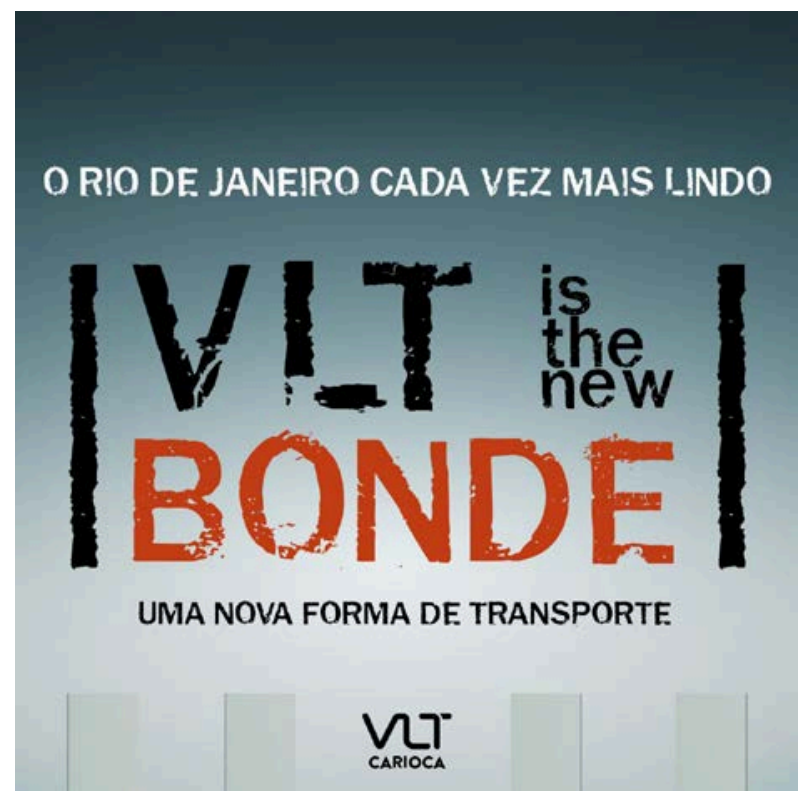

Figura 2: Cartaz de divulgação da Concessionária "VLT Carioca". Página Oficial no Facebook, 2016.

Ao traçar paralelos entre as transformações viárias ocorridas nessa região histórica - que por um longo período recente vinha dominada por um padrão modernista submissa aos carros, e que se adaptou para acomodar essa nova configuração de compartilhamento com o VLT - com o padrão de urbanização neoliberal imposto pelos grandes projetos urbanos, entendemos que a peça do VLT se insere nesse circuito de valorização que Cuenya (2011) descreve, baseado nos "consumidores VIP", interessados em torres de vidro, e empreendimentos cada vez mais luxuosos com assinaturas de renomados escritórios de arquitetura nacionais e estrangeiros.

\section{CONSIDERAÇÕES FINAIS: ENTRE DISCURSOS E RESULTADOS}

Como vimos, estes novos padrões exigidos por este novo circuito econômico impõe mudanças nos espaços públicos, que vão se especializando e homogeneizando. Dentre esses padrões comuns, destaca-se a 
excelência nos padrões de acabamento, implicando em edifícios com arquitetura icônica vanguardista e espaços públicos vibrantes com muito espaço para o consumo.

Toda essa transformação guarda relação com o conceito de reinvenção urbana que trouxemos neste trabalho. Os ícones e o marketing aliam-se para forçar um processo que é o de resignificar uma área relegada da cidade. Por isso faz todo o sentido utilizar peças-chave que trazem consigo um discurso pré-estabelecido para formatar um novo lugar urbano.

Moura (2017) nos traz uma importante perspectiva teórico-conceitual, na qual o ícone pode ser definido como um signo que estabelece com o representado uma relação de verossimilhança, de tal modo que pode "substituir e manter o significado da coisa representada mesmo em sua ausência" (Paiva, 2014:108 apud Moura, 2017:3). O autor ainda nos mostra que, "se nos atermos ao campo da semiótica pierciana, verificamos que a noção de ícone é forjada a partir de uma relação muito específica entre a representação e o representado, entre o signo e o objeto" (Moura, 2017:3).

As discussões de ícones perpassam a arquitetura e o urbanismo a muitos séculos, com edifícios que atravessam a história representando normas, valores e relações de poder. Moura (2017) nos lembra que não são apenas as instituições religiosas e políticas que procuram impor suas ideias por meio dos espaços, mas também as lógicas econômicas que regem a sociedade. É o caso, portanto, do VLT, ícone urbanístico que se associa nessa lógica como instrumento específico para fundamentar a criação de uma imagem positiva da cidade, visto que atua como atrativo para os novos capitais e pessoas "do tipo certo" (Harvey, 2012:91 apud Moura, 2017:4). Assim, na condição pós moderna que nos encontramos, o VLT chega e "deverá ser consumido como se fosse um gadget urbano, uma atualização da experiência de circular na cidade, uma espécie de Bonde 2.0" (Ribeiro, 2017:16).

A transformação, sabemos, vai muito além da inserção do VLT, e envolve toda uma modelagem da paisagem. Faz-se uma adaptação da forma da cidade para um determinado "tipo de conteúdo", ao estilo do "tipo certo" de pessoas falado por Harvey. Ribeiro (2017) fala que, no caso do Porto Maravilha essa alteração é processada a partir de substituições de equipamentos (retrofits que transformam edifícios em museus, por exemplo), construções de novos equipamentos (sobretudo "turístico/culturais", de museus a estações de teleféricos), instalações de nova infraestrutura (calçamento com materiais de luxo, cabeamento de redes de fibra ótica etc.

Tudo isso não é restritivo à zona portuária do Rio de Janeiro. Ainda no século XX, segundo Mendonça (2014), iniciou-se um processo de valorização das áreas centrais e portuárias, sendo a renovação urbana de frentes d'águas marítimas ou fluviais, os chamados "waterfronts", "considerada como uma das tipologias mais polêmicas dos projetos urbanos em larga escala, pelo grau de complexidade que apresentam e pela probabilidade de envolver conflitos de interesses" (Mendonça, 2014:65).

Foi assim que chegou a vez do Porto Maravilha. A área também foi impulsionada por arquiteturas vanguardistas. Da mesma forma que o VLT, ícone urbanístico da área, as novas formas arquitetônicas assumem uma "forma de propriedade que não pode ser generalizada", cuja exclusividade pode ser encontrada não apenas nas suas formas visualmente espetaculares, mas no poder monopolista da assinatura de um arquiteto laureado (Arantes, 2012:55 apud Moura, 2017:4).

Destaca-se na região o Museu do Amanhã, com a assinatura do star-architect espanhol Santiago Calatrava e o MAR (Museu de Arte do Rio), que uniu através de uma intervenção contemporânea o antigo Palacete Dom João VI, tombado e eclético, e o edifício vizinho, de estilo modernista (figura 3). Os antigos galpões ociosos agora estampam grafites artísticos, como o do brasileiro reconhecido mundialmente, Eduardo Kobra (figura 4) e contam com atividades e exposições de patrocinadores Olímpicos, como por exemplo o galpão da Coca-cola, assinado pelo croata radicado no Brasil Marko Brajovic. 

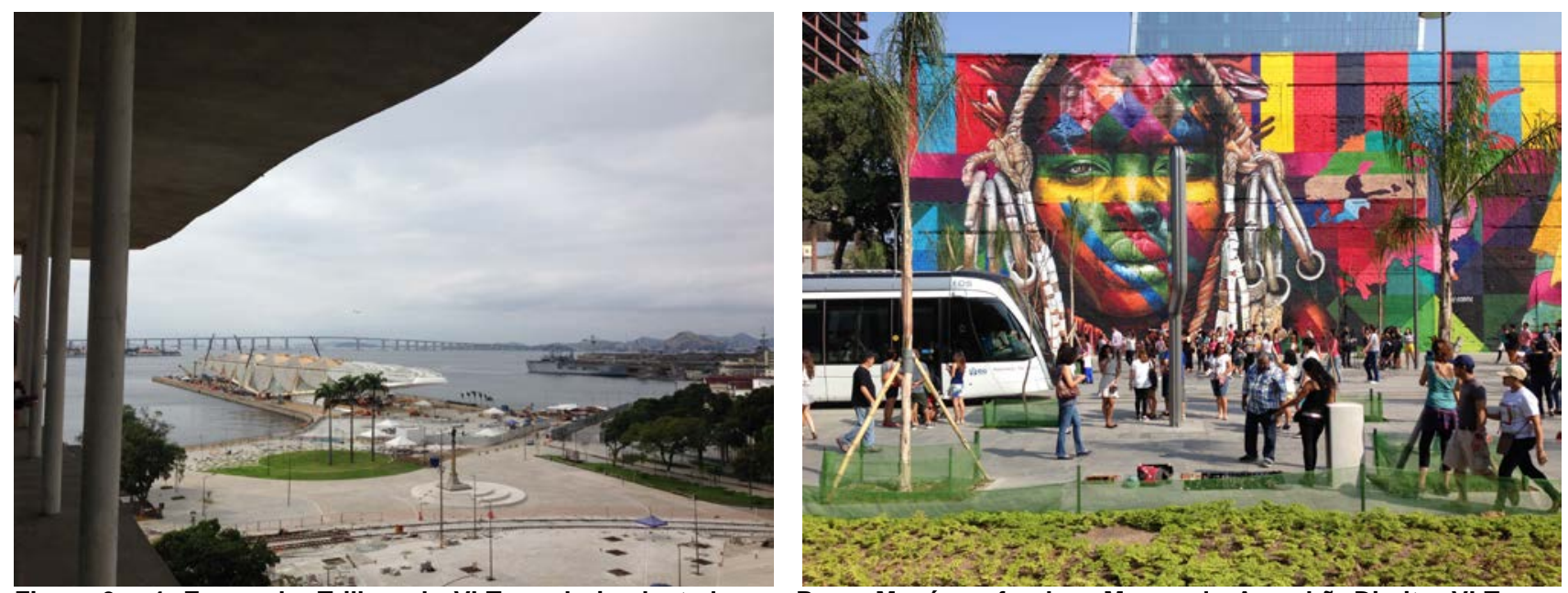

Figura 3 e 4: Esquerda: Trilhos do VLT sendo implantados na Praça Mauá, ao fundo o Museu do Amanhã; Direita: VLT em funcionamento durante as Olimpíadas na área portuária, em frente ao galpão (ainda sem uso na época) grafitado por Kobra. Acervo do autor (jul/2015 e ago/2016)

O VLT Carioca impõe-se como um grande conector de todas essas novas atividades, sendo um sistema funcionalmente adequado para cumprir esse papel de interligar todas essas novas obras, pois tem traçado fixo, e permite confiabilidade na regularidade temporal, além de toda a sua capacidade de dialogar bem com a paisagem e os modos ativos. Essa escolha fica explícita em uma das diretrizes do traçado, que é "interligar os principais eixos de transporte da área central, e seus pontos turísticos e/ou de grande circulação, atuais e projetados para a região" (Grupo CCR, 2011a:50).

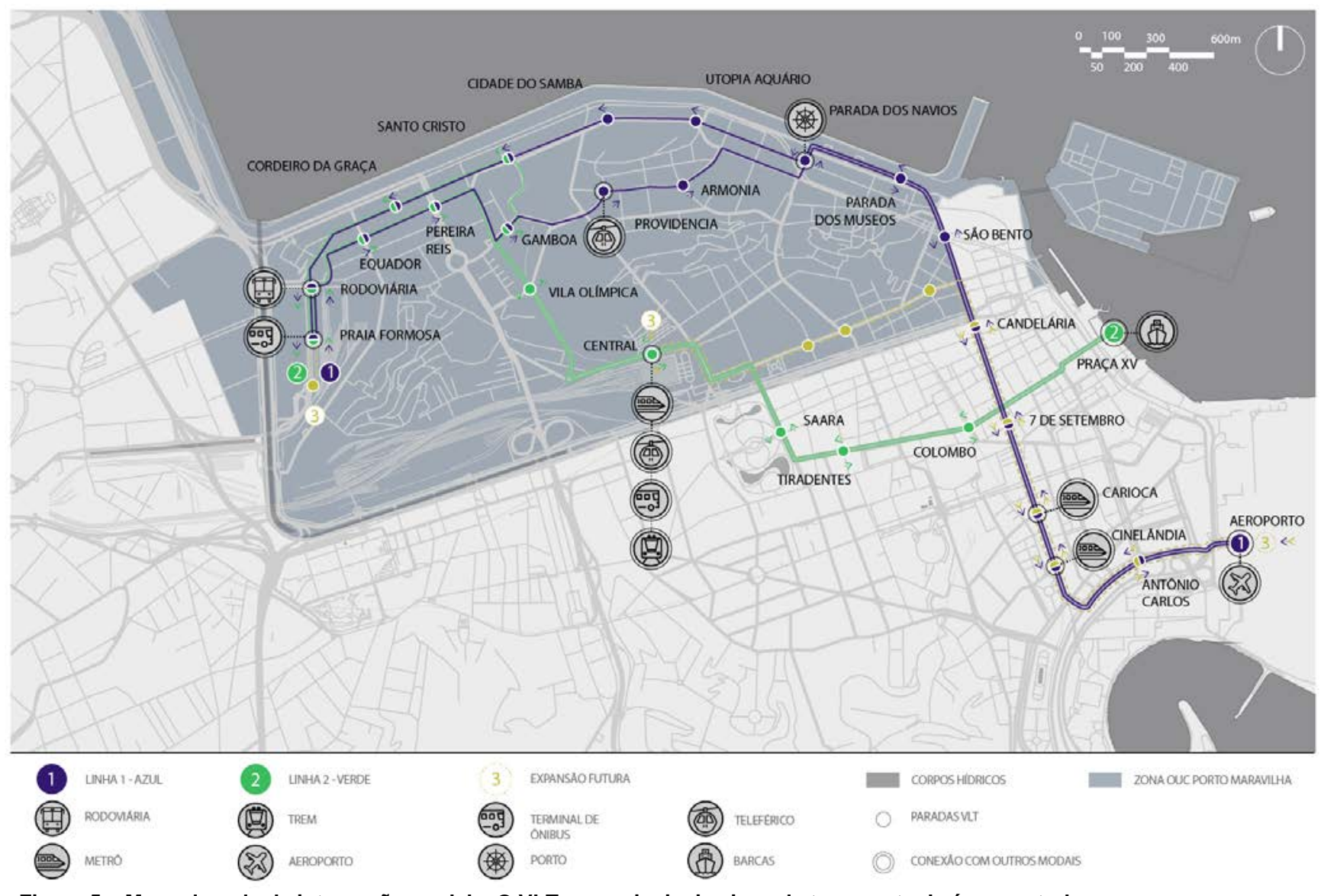

Figura 5 - Mapa da rede de integração modal - O VLT e os principais eixos de transporte da área central Elaborado pelo autor 
A linha 1 inaugurada nas Olimpíadas liga os principais equipamentos modais de atração de fluxos externos ao município: o Aeroporto e a Rodoviária. Entre esses dois pólos destaca-se a integração com a Parada dos Navios, garantindo a intermodalidade dos turistas advindos de cruzeiros de outros países.

A linha 2 faz a interligação intra-centro, fazendo integrações com estações intermodais importantes para a cidade, como a Central, que liga o metrô, trem, teleférico e ônibus, e a Praça XV, que possibilita a integração com o Terminal de Barcas.

A pesquisa realizada pelo IBOPE no final de 2016 indicava que 71\% dos usuários, eram das classes A e B, número curioso se confrontado com o perfil de utilização do transporte público da população brasileira, onde historicamente as classes mais dependentes são as $C, D$ e $E^{4}$. Os dados da análise do DATAFOLHA em 2017 revelam uma estabilidade nesse perfil "diferenciado"; a linha 1 apresenta uma média de 68\% dos usuários com escolaridade encaixada no perfil de ensino superior completo. Embora seja pequena, existe uma diferença de classe social entre as linhas 1 e 2, já que as classes C e D na 1 atingem 34\% e na 2, 42\% - destacando-se a classe $D$, que ocupa $5 \%$ na linha 2 , enquanto na 1 , apenas $1 \%$.

Obviamente todas essas ações incidem sob um novo estilo de vida, e atingem em grande medida um estrato específico da população. Cuenya (2011) diz tratar-se de um binômio que reflete bem a articulação entre sociedade e espaço:

Em suma, as aspirações, demandas e estilos de vida da elite que decide viver e trabalhar nos espaços da nova centralidade, (interatuando dialeticamente com o marketing dos empresários) incidem no perfil dos lugares, em termos de tipo de usos, hierarquia, qualidade físico-ambiental, conforto urbano, inovação no desenho, segurança e exclusividade de imóveis e espaços (Cuenya, 2011:196, tradução nossa).

São muitos os novos espaços surgidos; em um esforço de levantamento dos novos projetos empreendidos na área de entorno do Porto Maravilha, resolvemos separar em Público, Corporativo/Hoteleiro e Residencial (ver figura 6). Surpreende o número de equipamentos públicos construídos ou reformados sobre o privados, sejam comerciais ou residenciais. A grande maioria está localizada ao longo das linhas do VLT, principalmente a linha 1, com uma notável concentração de atrações no raio de abrangência da Praça Mauá. A relação se confirma na prática com os dados repassados pela Concessionária VLT Carioca, com a linha 1 possuindo carregamento médio de 37 mil usuários/dia, enquanto que a linha 2 possui uma média de 19,5 mil usuários/dia.

O cruzamento dos dados dos mapas das figuras 6 e 7 também reforçam a conjectura apontada por toda a avaliação conceitual do desenho dessas linhas, que ficam provados com os dados de que $83 \%$ da demanda de passageiros se concentra no trecho entre a parada Santos Dumont e a Utopia/Aquário. O restante do trecho, que não acompanhou todo o processo de renovação do trecho anterior responde pelo restante dos usuários, com $17 \%$ da demanda entre a Cidade do Samba até a Rodoviária.

\footnotetext{
${ }^{4}$ Dados da CNT, NTU (2017) mostram que o percentual de uso do transporte coletivo em 2017 nas classes A e B estão em torno de $24 \%$ e $40 \%$, enquanto que nas classes C e D/E chegam a $53 \%$ e $60 \%$.
} 


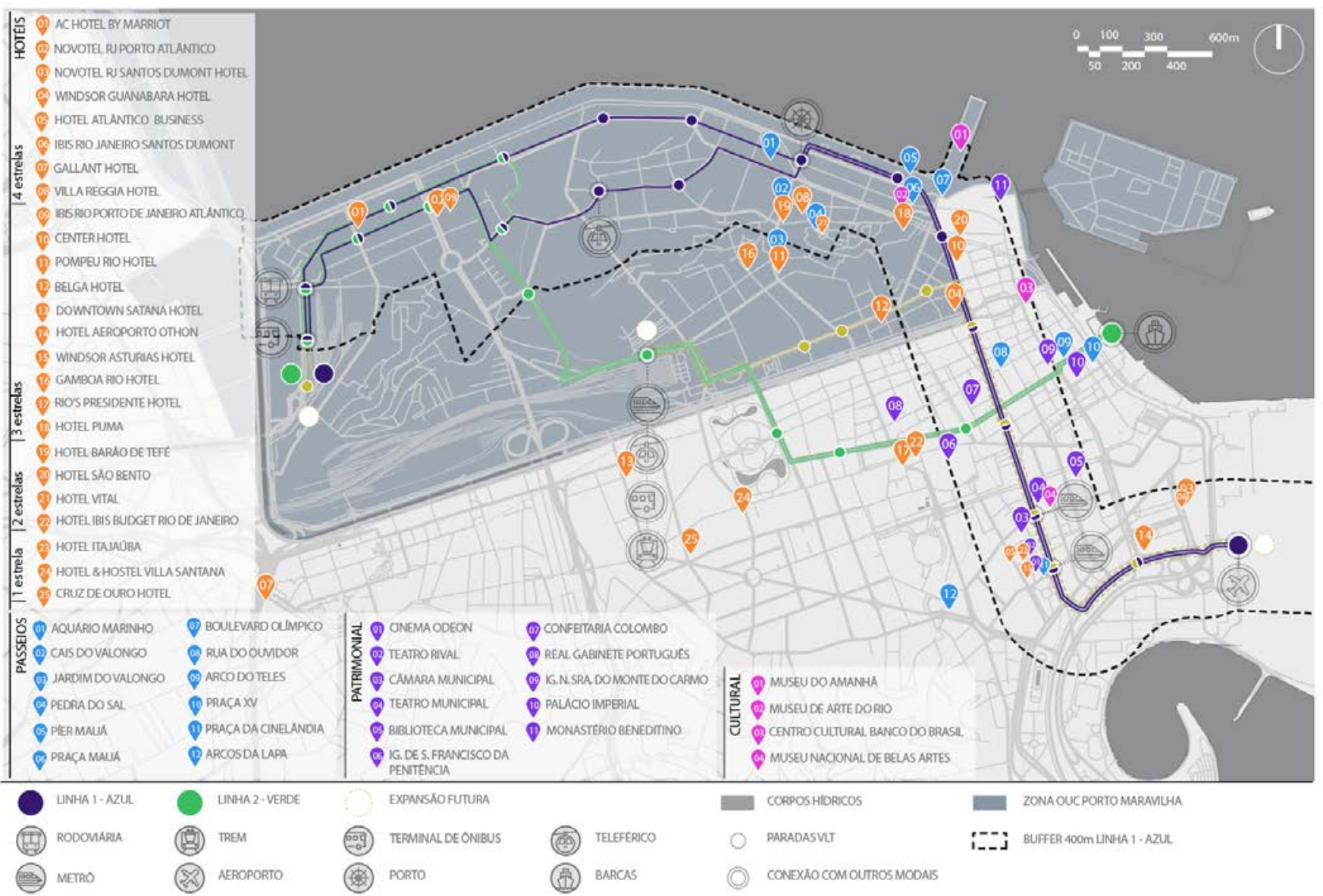

Figura 6 - Mapa da rede evidenciando os principais equipamentos/pontos turísticos da região - aeroportos, hotéis, museus, fluxos

Elaborado pelo autor

Esses novos espaços na própria Olimpíadas foram tratados como espaços para consumidores VIPs. A Praça Mauá, epicentro de toda a revitalização, tinha preços altíssimos nos food trucks e comércios do entorno. Assim, com a operação ainda nem concluída o espaço já ia assumindo uma diferenciação a partir da renda, "aqueles que não possuem esse nível de renda não podem incorrer nesses gastos, o que faz com que o mesmo consumo se converta em sinal de status social" (Jaramillo, 2003 apud Cuenya:197).

Werneck (2017) nos lembra que, pelo consórcio ser responsável pela provisão de serviços na área portuária, ele possui ingerência sobre os espaços públicos, e que a empresa, inclusive, vem restringindo sua ocupação e negociando junto ao poder público a realização de eventos públicos. Um exemplo que a autora nos traz, e que ficou muito famoso na mídia durante o período olímpico foi o caso das baianas que vendiam acarajé, que foram proibidas de vender os quitutes na Praça, sob a justificativa de que o azeite de dendê poderia vir a manchar a pavimentação, um exemplo que "parece ser trivial, mas demonstra como os agentes privados hoje atuam sobre o cotidiano da área portuária" (Werneck, 2017:14).

Essas diferenciações vão gerando uma série de efeitos colaterais mais amplos na sociedade, que culminam por gerar um processo de gentrificação espacial, com a "expulsão branca" dos habitantes menos solventes. Ribeiro (2017) trata esse processo como uma "higienização do século XXI", já que a formatação de um espaço padrão, standard termina por promover "a remoção de moradores pobres, a destruição, sem deixar vestígios, da força de trabalho informal através da violenta proibição de ambulantes autônomos nessas áreas" (Ribeiro, 2017:8).

Essa expressão socioeconômica demonstrada na figura 6, com o mapa dos projetos implantados nos mostra por exemplo a explosão desses equipamentos corporativos todos como de alto padrão, assim como o residencial, que embora em baixa expressão em comparação com os demais são todos empreendimentos de acesso para a alta renda. Desta forma, a conjunção das análises configuracionais e socioeconômicas vão reverberar no ambiente, proporcionando impactos diretos nos modos de vida e urbanidades. 
Assim, conforme a análise que Cuenya (2011) faz para os usuários da região revitalizada do Porto Madeiro em Buenos Aires, os frequentadores de mais baixa renda da região são sempre "visitantes" e nunca habitantes: "o mundo que se vê é o mundo dos trabalhadores da construção e vendedoras de comida, um mundo que nunca se cruza com o outro, o dos 'habitantes"' (Cuenya, 2011:200).

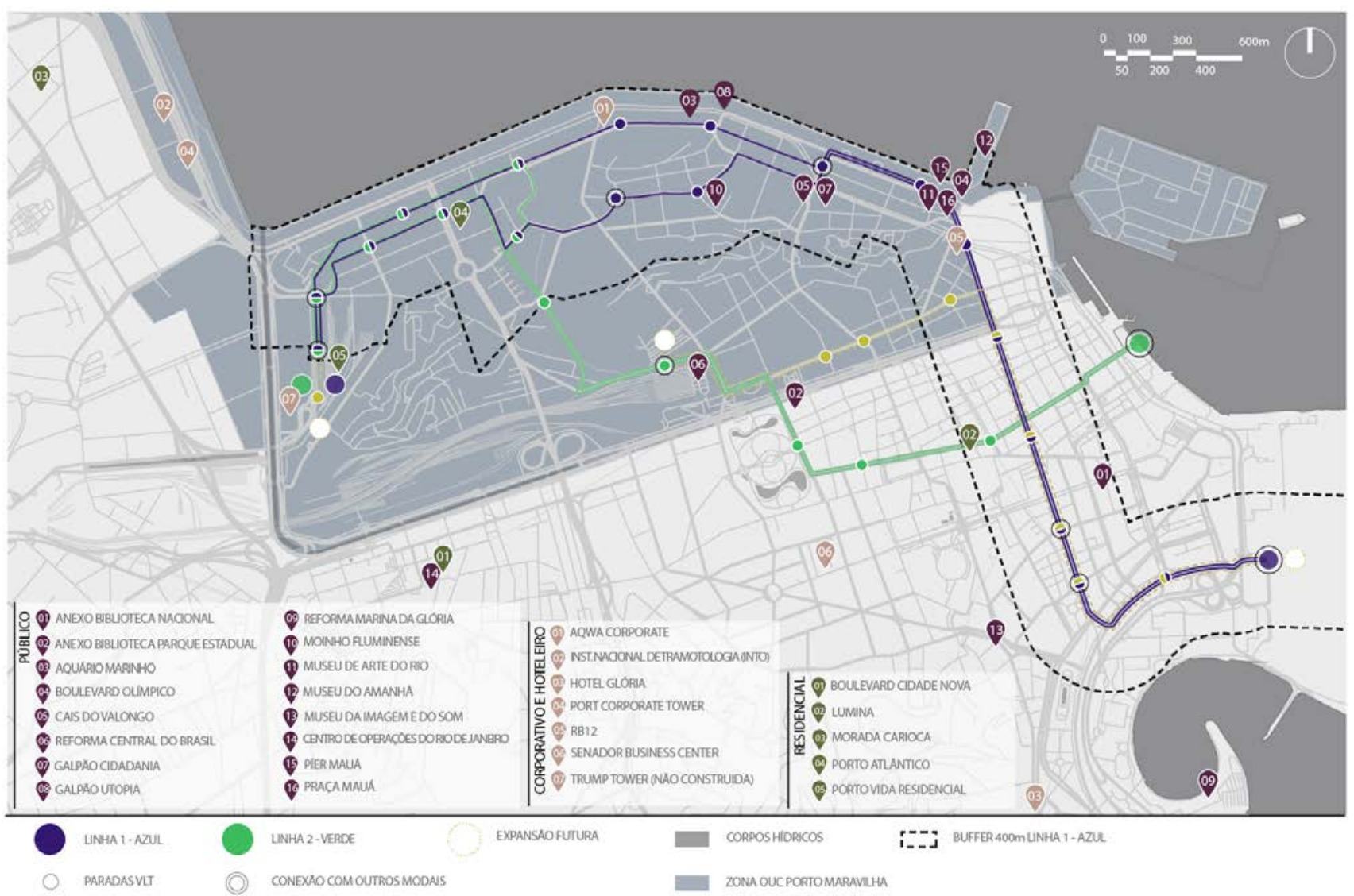

Figura 7 - Mapa da rede relacionando o traçado com os projetos implantados a partir da OUC Porto Maravilha Elaborado pelo autor

\section{BIBLIOGRAFIA}

BOYER, M. (1998). The city of colletive memory: its historical imagery and architecture entertainments. Cambridge: MIT Press.

CARERI, F. (2009) Walkscapes. El andar como práctica estética. Land\&Scape, $1^{\circ}$ edición, Barcelona: Gustavo Gili.

CASTELLS, M, BORJA, J. (1997). Local y global. Madrid: Taurus.

CASTRO, M. (2007). O Bonde na cidade - transportes públicos e desenvolvimento urbano. São Paulo: Annablume.

CUENYA, B. (2011). Grandes proyectos y sus impactos en la centralidad urbana. Cad. Metrop., São Paulo, v. 13, n. 25 , pp. $185-212$.

FARRET, R. (1984). Impactos sobre a Estrutura Urbana das Intervenções no Sistema de Transporte. Revista dos Transportes Públicos, ANTP, ano 7, n. 26, p. 21-33, dez.

GEHL, J. (2013). Cidades para pessoas. São Paulo: Perspectiva.

CGU - CONTROLADORIA GERAL DA UNIÃO. Coordenação-Geral de Auditoria da Área de Cidades. Relatório de Avaliação dos Resultados da Gestão. Brasília, DF, 2016. 77p. 
GRUPO CCR. (2016). Estudo preliminar e provisório de demanda para o sistema de Veículo Leve sobre Trilhos na região portuária e centro do Rio de Janeiro. Anexo 7 - Projeto Funcional. Rio de Janeiro. [2011]a. Disponível em: <http://www.mobilize.org.br/midias/pesquisas/projeto-funcional-do-vlt-porto-maravilha.pdf>. Acesso em: 2 jun.

IZAGA, F. (2009). Mobilidade e Centralidade no Rio de Janeiro. 282 p. Tese (Doutorado) - UFRJ. Rio de Janeiro.

KARA JOSÉ, B. (2012). 'As intervenções 'res' - contribuindo para o debate'. (Artigo). Disponível em: <http://www1.sp.senac.br/hotsites/campus_santoamaro/Simposio_Arquitetura_Urbanismo/2012/arquivos/Be atriz_Kara.pdf>. Acesso: 01 jul.

LAKATOS, E; MARCONI, M. (2003). Fundamentos de metodologia científica. 5. ed. - São Paulo: Atlas.

MARICATO, E. (2008). A cidade e o automóvel. Ciência \& Ambiente, v.37, p.5-12.

MENDONÇA, A. (2014). Grandes Projetos Urbanos e Gestão Pública: A Renovação da Área Portuária do Recife. Dissertação de Mestrado, MDU/UFPE, Recife. 173p.

MOURA, H. (2017). O papel dos novos ícones urbanísticos e arquitetônicos na produção do espaço urbano no Rio de Janeiro: Um estudo sobre a região portuária. In: XVII Encontro Nacional da Associação de PósGraduação e Pesquisa em Planejamento Urbano e Regional, São Paulo.

PORTAS, N. (1985). Notas sobre a intervenção na cidade existente. In: Revista Sociedade e Território, No 2, p. 8 . Porto: Edições Afrontamento.

PROJETO PORTAL. (2003). Transportes e Uso do Solo. Disponível em: <www.eu-portal.net>. Acesso: 01 jul. 2017.

RIBEIRO, C. (2017). Paisagem urbana do capitalismo dependente: acumulação no processo produtivo do espaço urbano e o fetiche da mobilidade no Rio de Janeiro. Anais do Colóquio Internacional Marx e o Marxismo 2017. Niterói. 2017. ISBN: 978-85-228-1279-0. Disponível em: <http://www.niepmarx.blog.br/MM2017/anais2017.htm>. Acesso: $30 \mathrm{dez}$.

SCHADE, E. (2011). El modelo Barcelona de espacio público y diseño urbano: el espacio público en la inserción del tranvia - el caso del tram Besòs. 133 p. Tese (Mestrado) - Universitat de Barcelona/Facultat de BellesArts. Barcelona.

SORT, J. (2005). Redes Metropolitanas. Barcelona: Gustavo Gili.

VAINER, C. (2000). Pátria, Empresa e Mercadoria. Notas sobre a Estratégia Discursiva do Planejamento Estratégico Urbano, In O. Arantes; C. Vainer; E. Maricato. A Cidade do Pensamento Único. Desmanchando Consensos. Petrópolis: Vozes.

VARGAS, H., CASTILHO, A (coords.). (2006). Intervenções em centros urbanos: objetivos, estratégias e resultados. Barueri, SP: Manole.

WERNECK, M. (2017). Interesses em jogo na cidade olímpica: o Porto Maravilha e seu arranjo institucional e financeiro. XVII Encontro Nacional da Associação de Pós-Graduação e Pesquisa em Planejamento Urbano e Regional (São Paulo). 